\title{
Perception of God and Paranoia among Iranian University Students
}

\author{
Shideh Fasahati, Seyed Mohammad Kalantarkousheh \\ Department of Counseling, Faculty of Psychology and Education, Allameh Tabataba'i University, Tehran, Iran \\ Email: fasahati@gmail.com, Kalantar.counseling@gmail.com
}

Received 8 April 2014; revised 6 May 2014; accepted 1 June 2014

Copyright (C) 2014 by authors and Scientific Research Publishing Inc. This work is licensed under the Creative Commons Attribution International License (CC BY). http://creativecommons.org/licenses/by/4.0/ c) (i)

\begin{abstract}
This study examined the correlation between types of perception of God and paranoid thoughts among 312 randomly sampled students-175 female and 137 male-in the Azad Islamic University of Tehran in Iran. Two survey questionnaires were administered to the participants through the University's website-one assessing their perception of God (Lawrence, 1997), and the other to assess the occurrence of paranoid thoughts among them (Derogatis, Lipman, \& Covi, 1973). Data were analyzed using correlation coefficients and regression methods. The results show that only the negative perception of God correlates with paranoia in both males and females, while the perception of God's blessings in one's life correlates with paranoid thoughts only among male students. Students with a positive perception of God experience less paranoia than students with negative perception of God-a finding that may actually suggest that positive spirituality/religiosity holds positive and therapeutic benefits for the paranoid.
\end{abstract}

\section{Keywords}

Paranoia, Paranoid Thoughts, Negative Thoughts, Perception of God, Iranian Students

\section{Introduction}

Through the spiritual chronicles of time, it appears that the most forgiving and loving of men had built their psycho-spiritual nature on the basis of first acknowledging and viewing God as the epitome of infinite mercy, kindness and love. It is no wonder, then, that many religious texts emphasize that one's terms of endearment with God is a significant determinant and motivation in offering one's best to others, in all relationships (Brown \& Miller, 2005), since "the love of God"-much more than only "the fear of God"-would cause one to develop a "merciful" view of others, by natural extension of the Divine love one feels within one's core. As Imam Ali (A.S.) once said: "The one who amends his/her relationship with God, God will also help them to have better 
relationship with other people” (Allame Majlesi, 2009).

Sims (1992) defined spirituality as, in essence, the personal quest for understanding one's relationship with God, and understanding the meaning and purpose of one's life in all its complexity-the outcome of which imparts critical influence on one's feelings towards oneself, God and others in general. The tenets of Abrahamic religions in this context seem to define this personal quest as, essentially, a quest towards spiritual perfection. Belief in God and his revelations are only two of the primary and operative pillars of the quest of spirituality, whose tangible manifestations include the glorification of God and various rituals in holy places like churches, synagogues and mosques. Over and above this over-simplification, the crux of spirituality lies in first understanding one's relationship with the creator-an understanding that can begin and grow only when one has established the appropriate and adequate perception of God.

Sorenson (2004) believes that the light in which God is perceived—viz., positively or negatively—is really subject to the individual's history of interpersonal experiences with God and, subsequently, the individual's interpretation of those experiences - which is essentially in light of the traditions that mould their psyche as under the object-relations theory. Indeed, one's perception of God is influenced by various elements such as one's destiny of religious and spiritual experiences-and to what extent one is capable of sensing and understanding the realities of such experiences - which are ever-evolving in the course of one's life. Interestingly, to relate the perception of God with more tangible outcomes, some research has indicated that a positive perception of God has an inverse [significant] relationship with the occurrence of several psychological distresses (Weber, Pargament, Kunik, Lomax, \& Stanley, 2012).

In their analysis of the relationship between psychological disorders and types of perceptions of God, Koohsar and Bonab (2011) made the striking observation that: people with positive mental perception of God suffered far less personality disorders, physical ailments and compulsive obsessions than those with negative or uncertain perceptions. Additionally, Tisdale et al. (1997) found meaningful correlations between a positive perception of God and self-acceptance as well as acceptance of others. Further, the aforementioned studies found that people with a positive mental perception of God were more at ease in interacting with other people and had less anxiety, fear, hatred and paranoia compared to people with negative or uncertain perceptions of God.

In the scope of this paper, a clear definition of paranoia must be provided here. The DSM IV (Flores, 2012) considers paranoia as a mental disorder whose key symptoms are: extensive and unjustified lack of trust in others and negative interpretation of others' behavior. People suffering from this personality disorder usually believe that they are being manipulated or taken advantage of by others without having a witness to their assumptions. Their mind is frequently occupied with unexplained suspicions or doubts, and mistrust of friends and family around them. Such people reportedly feel like they are recipients of continuous hatred and humiliation and, naturally, find it difficult to overcome or forget the consequent negative feelings that stem from their perception of having been wronged by others.

In light of the critical influence of spirituality on an individual's entire psychological life and outcomes, and in light of groundbreaking findings that indicate the superior mental health merits incurred by a positive perception of God-it becomes only necessary to examine the factors that influence an individual's perception of God.

Hill and Hall (2002) had established the effect of elements such as family, society, interactions with people and religious learning/activities on a person's understanding of God. Newton and McIntosh (2010), in their works on the impact of the parents' perception of God on their empathetic potential, discovered that people with positive perceptions of God have enhanced capacities for psychological comforting and that they face challenges more positively. People, who have experienced warm and supportive relationship with their parents have higher self-esteem and believe God to be kind, giving and caring-wherein they develop a perception of God as a loving God, and a spirituality that is founded more on the "love of God" as opposed to "the fear of God". Earlier research has shown that people with safe [family/relationship] attachments had a more positive perception of God, felt protected and continually embraced by God, and felt closer to the loving Creator (Kirkpatrick, 2005).

Further, researchers such as Jonker and collegues (2008) have shown that people with positive perception of God are less stressed and anxious compared to those whose perception of God is founded only on the fear of God and not so much, or at all, on the love of God, and who, consequently, suffer from heightened anxiety and anger. Kirkpatrick and Shaver (1992) had shown how people with a negative perception of God-a perception that stems from negative life experiences in early life-become reportedly lonelier. However, in contrast, people with a positive perception of God have stronger faith and place far greater trust in the Creator-believing that it is only by his command all things happen, and that he answers all prayers-which greatly abates any feeling of 
loneliness.

It is no surprise, thus, to find that a lot of people suffering from mental illnesses have negative perceptions of God as well, and suffer from depression, social anxiety and paranoia-which may all be rooted in their negative perception itself, their inability to understand the wisdom behind why God had put them through such tests.

It may be said that throughout the history of man, spirituality has unfolded in two distinct approaches to faith in God-one that is founded on the love of God which is the uplifting or encouraging path in the spiritual quest and the other on the fear of God which serves as a sin-deterring mechanism. Frequently, the latter view leads to the negative perception of God as essentially a punisher, and reduces spirituality and religion to a mere set of rules to be complied with. This view also robs people of the experience of engaging their utmost intellect and emotional beings in the rationalization, discovery and joy of: understanding the true essence of God, realizing the spiritual potential within oneself, and lovingly helping others to reach their own spiritual potential as well. Thinking of God as a punisher prevents people from feeling close/attached to God, which eventually prevents them from achieving complete trust in God and his divine plan. Further, people who view God as a punisher fail to adequately handle the frailties associated with being human. When such people commit a sin, their negative perception of God and their failure to view God as a loving and forgiving guide prevents them from seeking God's forgiveness, thereby creating their own obstacles in their relationship with God. As (Koohsar \& Bonab, 2011) explained, "for those with a negative perception of God, committing a sin only leads to a negative self-perception on the sinner's part (and not to repentance and God-attachment), which then disturbs their connection with God and makes them feel neglected and unloved by God”.

Out of all mental disorders that were found to occur in tandem with a negative perception of God, paranoia was the one that surfaced most frequently in most research in this context. Flannelly and colleagues (2010) examined the relationship between mental illness and types of perceptions people have of God. They found that people who were less paranoid about others also had positive perceptions of God and, on the other hand, people who were paranoid and/or had fractured psyche had a cold, distanced and unemotional perception of God. In support of these findings, other researchers discovered that psychologically impaired individuals were more likely to harbor a negative perception of God compared to their psychologically sound counterparts (Verhagen, Van Praag, Lopez-Ibor, Cox, \& Moussaoui, 2010).

Having identified the factors that influence one's God-perception, and the effect of one's God-perception on one's mental health - it must also be stated that one's God perception may not only be the cause of one's mental ailments, but it may also found the very spiritual foundation for optimum mental health. The meta studies on religious challenges by Pargament (1997) had some very revealing findings that established the crucial need for positive God-perceptions in augmenting and sustaining mental health. Pargament (1997) identified that individuals who have experienced rejection from religious communities are most prone to feeling confused and let down, since such rejection attacks the very fabric and validity of their own spirituality and God-perceptions. These individuals have a built up anger towards others and have lower mental health compared to those who haven't gone through such rejection. In his research, Pargament concluded that the type of understanding a person has of God founds the very self-recognition capacity and dynamics within an individual, which imparts a determining effect on the individual's choices on how to face mental challenges in life. Not surprisingly, thus, The Group of Encouraging Psychology (1968), in the United States of America, had formally stated the importance of religion's role on mental disorders, particularly schizophrenia and paranoia.

Finally, although the western cultures had witnessed much research on the link between God-perception and paranoia, such studies are yet to be substantially undertaken in the context of an eastern or Islamic culture. The first ever studies that exist in the eastern context were conducted on Iranian people and culture by Koohsar \& Bonab (2011), who studied the aforementioned link among students of medical universities across the country. It was found, therein, that students with a positive perception of God had a lower incidence of paranoia than those with a negative perception of God.

Therefore, the aim of this research was to study the relationship between God-perceptions and paranoia among Iranian university students. The research set out to examine the perception of God (impact of God in life, God's blessing and negative perception of God) among the students, and whether there exists any definitive relationship between the God-perception and any occurrence of paranoia among this sample population. The study anticipated that the findings herein would have a great impact on human relations and family upbringing in the Iranian society. Last but not least, there are many psychological researches indicating gender differences (Kalantarkousheh, 2012) so that it is justifiable to pay attention to gender differences. 


\section{Research Methodology}

\subsection{Sampling Method and Data Collection}

The sample in this study consisted of 312 randomly selected students in the Azad Islamic University in Tehran, encompassing 175 female and 137 male students with ages ranging between 18 and 58. The average age of the participants was 23. Out of the 175 females, 4 were married and 151 were single, and among the 137 males, 14 were married and 123 were single.

Data was collected from student respondents of the Islamic Azad University in Tehran, Iran. A survey questionnaire by announcing, was administered among the students used the University's website and interested in participating in this study.

\subsection{Research Tools and Techniques}

The template is used to format your paper and style the text. All margins, column widths, line spaces, and text fonts are prescribed; please do not alter them. You may note peculiarities. For example, the head margin in this template measures proportionately more than is customary. This measurement and others are deliberate, using specifications that anticipate your paper as one part of the entire journals, and not as an independent document. Please do not revise any of the current designations.

\subsection{SCL90 Psychiatric Symptoms Survey}

The initial frame of this survey was designed to show various psychological aspects of physical and mental illnesses (Derogatis et al., 1973). Marashi (1996) in a Persian version of the questionnaire calculated the final coefficient in all features of these quizzes, which he reported to be between 0.80 and 0.93 using the bisection method and then between 0.80 and 0.93 using Cronbach's Alpha method. The overall consistency in this study was estimated to be about 0.80 , using Cronbach's Alpha method. It is worth to mention that in the present research, it was used Paranoia subscale of SCL90 using Persian version of it.

\section{Results and Findings}

\subsection{Descriptive Findings}

The results from answers to God perceptions and paranoid thoughts are detailed in Table 1. Skewness of each comparison was as followed: 0.72 for God's presence, 0.86 for God's blessing, 0.21 for negative perception of God, and 0.13 for paranoid thoughts. Kurtoses of these comparisons were: 1.17 for God's presence, 1.21 for God's blessing, 1.26 for negative perception of God, and -0.75 for paranoid thoughts.

Table 1 indicates that the highest average of the scales belonged to God's blessing. In other words, most participants believed in God's blessing in their lives. The lowest average was in the paranoid thoughts scale, which indicates that the prevalence of paranoid thoughts was rather sparse among the students. Standard deviations show lower distribution in the scale of God's presence in life and higher distribution is for the paranoia scale. The sample responded with a minimum rating in paranoid thoughts and a maximum rating in the scale of God's blessing.

\subsection{Hypotheses Results}

Table 2 summarizes the results of the data collected, and not the initial assumptions for this paper. Table 2 shows no meaningful correlation between God's presence and paranoid thoughts in female students $[\mathrm{r}(175)=$ $0.08, p>0.05$ ], thereby nullifying the first hypothesis on the possibility of such a correlation [for the case of females]. However, there was a meaningful correlation between negative perceptions of God and paranoia in females [r $(175)=0.26, p>0.05]$, thereby validating the second hypothesis on such a correlation [for females], wherein having negative perception of God encourages paranoid thoughts. Finally, no meaningful correlation was identified between God's blessing in one's life and paranoid thoughts among females [ $\mathrm{r}(175)=0.06, p>$ 0.05], which discards the third hypothesis on such a correlation for females.

Next, Table 2 reveals no meaningful correlation between God's presence in one's life and paranoid thoughts in males [r $(135)=0.06, p>0.05]$, thereby ruling out the hypothesis on such a correlation for males. However, a meaningful correlation did exist between the negative perception of God and paranoia in males $[\mathrm{r}(135)=0.21$, 
Table 1. Average, standard deviation, minimum and maximum.

\begin{tabular}{|c|c|c|c|c|c|c|}
\hline & & Maximum & Minimum & $\begin{array}{l}\text { Standard } \\
\text { deviatiod }\end{array}$ & Average & Alpha \\
\hline & Males & 6.4 & 1.4 & 60 & 4.3 & \\
\hline \multirow[t]{3}{*}{ God's presence } & Females & 6.4 & 4.1 & 50 & 5.3 & 0.68 \\
\hline & Total & 2.9 & 8.2 & 1.1 & 9.6 & \\
\hline & Males & 5 & 1 & 80 & 7.3 & \\
\hline \multirow[t]{3}{*}{ God's blessing } & Females & 9.4 & 1 & 70 & 7.3 & 0.86 \\
\hline & Total & 9.9 & 2 & 5.1 & 4.7 & \\
\hline & Males & 5 & 0 & 0.7 & 6.2 & \\
\hline \multirow[t]{3}{*}{ Negative perception of God } & Females & 6.4 & 1 & 6 & 6.2 & 0.37 \\
\hline & Total & 6.9 & 1 & 1.3 & 2.5 & \\
\hline & Males & 7.3 & 0 & 0.9 & 8.1 & \\
\hline \multirow[t]{2}{*}{ Paranoia } & Females & 4 & 0 & 1 & 2 & 0.80 \\
\hline & Total & 7.7 & 0 & 9.1 & 8.3 & \\
\hline
\end{tabular}

Table 2. Correlation between perception of god and paranoid thoughts metrics.

\begin{tabular}{|c|c|c|c|c|c|c|}
\hline \multirow[t]{2}{*}{ Variable } & \multicolumn{2}{|c|}{ Total: $(n=312)$} & \multicolumn{2}{|c|}{ Males: $(n=137)$} & \multicolumn{2}{|c|}{ Females: $(n=175)$} \\
\hline & $r$ & $p$ & $r$ & $p$ & $r$ & $p$ \\
\hline God's presence and paranoia & 0.08 & 0.15 & 0.06 & 0.43 & 0.08 & 0.27 \\
\hline Negative perception of god and paranoia & 0.24 & $0.0^{* *}$ & $0.21^{*}$ & $0.01^{*}$ & $0.26^{* *}$ & $0.0^{* *}$ \\
\hline God's blessing and paranoia & 0.1 & 0.05 & 0.16 & 0.05 & 0.06 & 0.37 \\
\hline
\end{tabular}

${ }^{* *}$ Validates when lower than $0.01 .^{*}$ Validates when lower than 0.05.

$p>0.05]$. Additionally, a meaningful correlation was found between paranoid thoughts in males and God's blessing in their lives [r $(135)=0.16, p>0.05]$ — wherein paranoia was found to be lower in males than in females, in connection to the perception of God's blessing in life.

Overall, and regardless of gender, the only and most meaningful correlation that emerged was that between a negative perception of God and paranoid thoughts. The more negative one's perception of God, the more paranoid thoughts the individual had [r $(312)=0.24, p>0.05]$. Thus, out of all nine hypothesis proposed, only three hypothesis where accepted (viz., the correlation between having a negative perception of God and paranoia among males, females and total sample population, respectively). Consequently, the only regression examined was with regards to having negative perception of God.

The results from the aforementioned regression estimation, as presented in Table 3, indicate that: only $7 \%$ of paranoid thoughts are predicted in females who have a negative perception of God [F $=13.17, p>0.05]$, while only $4 \%$ of paranoid thoughts are predicted in males with a negative perception of God [F $=6.79, p>0.05]$. Further, and regardless of gender, having a negative perception of God predicts only $6 \%$ of paranoid thoughts in people [F $=20.2, p>0.05]$. Summarily, the findings show that students with a positive perception of God experience less paranoid thoughts.

\section{Discussion}

This study had established a direct correlation between having negative perception of God and having paranoia and mistrust and doubt regarding others - a finding that is in harmony with that of other researchers such as Brown, Newton and Kirkpatrick. (Braam, Mooi, Jonker, van Tilburg, \& Deeg, 2008), who discovered a meaningful correlation between feeling dissatisfied with God and psychological ailments such as bitter disappoint- 
ment, guilt and various symptoms of depression.

This study also revealed that a negative perception of God (as characterized by, e.g., viewing God essentially as a punisher) is connected to feelings of deep-set guilt in the participants. In a supportive context, (Kirkpatrick, 2005) and (Newton \& McIntosh, 2009) had stated that: there is definite relationship between one's God-perception and the level of one's psychological health, wherein being dissatisfied with one's lot from God leads to disappointment, depression, guilt, anxiety, fear and other psychological ailments.

Although this study found no meaningful correlation between perceiving God's presence in one's life and paranoia, (Koohsar \& Bonab, 2011), in their study on an Iranian sample population, found that people who believed consciously aware of God's presence and influence in their lives had less doubt and mistrust towards others. Moreover, people who fully submitted to the acceptance of God's decree and authority over their lives had better mental health. Here, a differently structured survey to unearth more insightful findings Might actually yield results that may be compared to the findings of (Koohsar \& Bonab, 2011).

Next, this study found a positive and meaningful correlation between God's blessing and paranoid thoughts in males only. The explanation to this finding unfolds two distinct phenomena. On one hand, people who lose the connection with their own spirituality feel that they do not deserve God's kindness and blessings. On the other hand, when people feel that they deserve to be loved and forgiven, they can have a better relationship with God, who they view to be merciful and forgiving. Interestingly, many religious practices emphasize on having positive interactions with people, since it brings the positive psychological grounds (e.g., gratitude to God for being granted a happy social life) for a satisfying relationship with God. It must be noted here that the love of others and the love of God may well have its own mysterious, two-way equilibrium. As Prophet Mohammed (S.A.A.S.) had once stated: "The one who brings a positive and healthy mind towards God would be granted the same affirmative benefaction in his earthly relationships” (Allame Majlesi, 2009).

At this juncture, the impact of the perception of God upon human health is clear. Perceiving the Creator in profoundly positive light builds a spirituality that is founded essentially on the love more than the fear of God, and establishes a psyche that loves God with the reverent acknowledgement that His infinitely forgiving grace is incomprehensibly greater than even the greatest magnitude of our sins. People who have a close relationship with God and are continuously aware of the inordinate magnificence, mercy and love of the Creator towards His creation - are capable of bringing a blessed degree of sincerity, purity and truth in their relationships with others. Such relationships would create a human order where the average psyche refrains from committing sins, actively lives out the noblest human values, and faces difficulties and stress and life's many trials with graceful ease (Brown \& Miller, 2005).

Here, and conclusively, this study concurs with Brown and Miller's (2005) research findings on the positive connection between spiritual health and psychological health, wherein improving religious beliefs and having positive religious views have been found to enhance mental health. On that account, it may be recommended to administer religious/spiritual education as a remedy for people with paranoia, through appropriate consultants, institutions and clinics.

\section{Conclusion}

Finally, it must be clarified that the findings of this study on essentially university students are not generalizable to the elderly or to children, or to patients of mental disorders. Further, the scope of this study took the definition of paranoia to be of the clinical nature described in the DSM IV. In the mysterious domain of mental health, there may well be cases within the population where individuals have myriad valid reasons for being distrustful of others that may be difficult to substantiate, and those cases would not fall under the spectrum of paranoia described in this study.

\section{References}

Alavi, S. (2006). Survey of Relation between Feeling Guilty and Image of God in Cancer Patients. Tehran: Alzahra University.

Allame Majlesi, M. B. (2009). Relation with God. Bahar Al Anvar, 70, 384.

Braam, A., Mooi, B., Jonker, J. S., van Tilburg, W., \& Deeg, D. (2008). God Image and Five-Factor Model Personality Characteristics in Later Life: A Study among Inhabitants of Sassenheim in the Netherlands. Mental Health, Religion and Culture, 11, 547-559. http://dx.doi.org/10.1080/13674670701641886

Brown, S., \& Miller, W. R. (2005). Transformational Change. 
Derogatis, L., Lipman, R., \& Covi, L. (1973). SCL-90: An Outpatient Psychiatric Rating Scale—Preliminary Report. Psychopharmacology Bulletin, 9, 13.

Flannelly, K. J., Galek, K., Ellison, C. G., \& Koenig, H. G. (2010). Beliefs about God, Psychiatric Symptoms, and Evolutionary Psychiatry. Journal of Religion and Health, 49, 246-261. http://dx.doi.org/10.1007/s10943-009-9244-z

Flores, T. (2012). DSM-IV Manual diagnóstico y estadístico de los transtornos mentales. Masson.

Greenway, A. P., Milne, L. C., \& Clarke, V. (2003). Personality Variables, Self-Esteem and Depression and an Individual's Perception of God. Mental Health, Religion \& Culture, 6, 45-58. http://dx.doi.org/10.1080/1867467021000029381

Hill, P. C., \& Hall, T. W. (2002). Relational Schemas in Processing One’s Image of God and Self. Journal of Psychology and Christianity, 21, 365-373.

Jonker, H. S., Eurelings-Bontekoe, E. H. M., Zock, H., \& Jonker, E. (2008). Development and Validation of the Dutch Questionnaire God Image: Effects of Mental Health and Religious Culture. Mental Health, Religion and Culture, 11, 501-515. http://dx.doi.org/10.1080/13674670701581967

Kalantarkousheh, S. M. (2012). Gender as a Moderator in the Association of Self-Acceptance and Autonomy of Iranian University Students. Journal of Teaching and Education, 1, 39-46.

Kirkpatrick, L. A. (2005). Attachment, Evolution, and the Psychology of Religion. New York: The Guilford Press.

Kirkpatrick, L. A., \& Shaver, P. R. (1992). An Attachment-Theoretical Approach to Romantic Love and Religious Belief. Personality and Social Psychology Bulletin, 18, 266-275. http://dx.doi.org/10.1177/0146167292183002

Koohsar, A. A. H., \& Bonab, B. G. (2011). Relation between Quality of Image of God and Mental Health in College Students. Procedia-Social and Behavioral Sciences, 29, 247-251. http://dx.doi.org/10.1016/j.sbspro.2011.11.233

Lawrence, R. T. (1997). Measuring the Image of God: The God Image Inventory and the God Image Scales. Journal of Psychology and Theology, 25, 214-226.

Marashi, S. (1996). The Comparison of Social Adjustment and Mental Health among Employed and Unemployed War Handicapped Individuals. Ahwaz: Islamic Azad University.

Newton, A. T., \& McIntosh, D. N. (2009). Associations of General Religiousness and Specific Religious Beliefs with Coping Appraisals in Response to Hurricanes Katrina and Rita. Mental Health, Religion and Culture, 12, 129-146. http://dx.doi.org/10.1080/13674670802380400

Newton, A. T., \& McIntosh, D. N. (2010). Specific Religious Beliefs in a Cognitive Appraisal Model of Stress and Coping. International Journal for the Psychology of Religion, 20, 39-58. http://dx.doi.org/10.1080/10508610903418129

Sims, A. (1992). Symptoms and Beliefs. The Journal of the Royal Society for the Promotion of Health, 112, 42-46. http://dx.doi.org/10.1177/146642409211200110

Sorenson, R. L. (2004). Kenosis and Alterity in Christian Spirituality. Psychoanalytic Psychology, 21, 458. http://dx.doi.org/10.1037/0736-9735.21.3.458

Tisdale, T. C., Key, T. L., Edwards, K. J., \& Brokaw, B. F. (1997). Impact of Treatment on God Image and Personal Adjustment, and Correlations of God Image to Personal Adjustment and Object Relations Development. Journal of Psychology and Theology, 25, 227-239.

Verhagen, P. J., Van Praag, H. M., Lopez-Ibor, J. J., Cox, J., \& Moussaoui, D. (2010). Religion and Psychiatry: Beyond Boundaries. Wiley Online Library. http://dx.doi.org/10.1002/9780470682203

Weber, S. R., Pargament, K. I., Kunik, M. E., Lomax, J. W., \& Stanley, M. A. (2012). Psychological Distress among Religious Nonbelievers: A Systematic Review. Journal of Religion and Health, 51, 72-86.

http://dx.doi.org/10.1007/s10943-011-9541-1 